\title{
TRADUÇÃO DA BÍBLIA HEBRAICA EM DEZ VERSÕES BRASILEIRAS
}

\author{
Osvaldo Luiz Ribeiro ${ }^{1}$ \\ 1Faculdade Unida de Vitória \\ Vitória, Espírito Santo, Brasil
}

\begin{abstract}
Resumo: O objetivo do artigo é, com foco em quatro passagens, analisar dez diferentes versões brasileiras da Bíblia Hebraica. As quatro passagens analisadas nas dez versões são 1 Re 22,21 e Sl 53,3.5.7. O exercício constituiu-se das seguintes etapas: seleção de dez representativas versões vernaculares da Bíblia Hebraica, escolha das passagens a serem comparadas, tradução das passagens da Bíblia Hebraica, análise das passagens nas versões, da Bíblia Hebraica e da tradução autoral. O resultado revelou que, com apenas uma ou outra variada exceção, as versões cometem sistematicamente e em conjunto os mesmos tipos de desvios na tradução do texto hebraico. Uma vez que as passagens escolhidas não apresentam dificuldades significativas ao tradutor/intérprete, levantam-se hipóteses indiciárias para a explicação do resultado, como, por exemplo, pressões de ordem teológica operando no processo de tradução.
\end{abstract}

Palavras-chave: Tradução; Bíblia Hebraica; Exegese; 1 Re 22,21; Sl 53,3.5.7.

\section{TRANSLATION OF THE HEBREW BIBLE IN TEN BRAZILIAN VERSIONS}

\begin{abstract}
The aim of this article is to analyze ten different Brazilian versions of the Hebrew Bible focusing on four different passages, which are: 1 Re 22.21 and Sl 53.3.5.7. The methodology consisted of the following steps: selection of ten representative vernacular versions of the Hebrew Bible, the choosing of passages to be compared, translation of the Hebrew Bible passages, analysis of the passages in the Hebrew Bible, and the Hebrew Bible translation. The result revealed that, with only a few
\end{abstract}


exceptions, the versions systematically and jointly make the same types of deviations in the translation of the Hebrew text. Since the chosen passages do not present significant difficulties to the translator/interpreter, there are hypotheses for the explanation of the result, such as, for example, theological pressures operating in the translation process.

Keywords: Translation; Hebrew Bible; Exegesis; 1 Re 22:21; Ps 53:3.5.7.

\section{Introdução}

Nos ambientes especializados em tradução da Bíblia, as rotinas envolvidas são "exaustivas" ${ }^{1}$. Metzger fala de múltiplos manuscritos ("variant readings") a serem cotejados ${ }^{2}$, de dificuldades em determinar o sentido de palavras que ocorrem muito raramente nos textos bíblicos $^{3}$, de problemas na grafia secundária e das consequentes implicações semânticas da vocalização do texto massorético ${ }^{4}$, sem se esquecer das questões hermenêuticas ${ }^{5}$ peculiares ao processo de transferência de sentido da língua original para a língua do tradutor ${ }^{6}$. Nem por um momento se pretende desconsiderar essas dificuldades, que Metzger apenas esboça. Todavia, qualquer um que se engaje no processo de traduzir a Bíblia Hebraica e, por isso, vê-se, por força de ofício, obrigado a comparar as diferentes versões vernaculares, defronta-se com um problema que não parece ter qualquer ligação com as dificuldades de que tratou o autor mencionado. Considerando-se que "atualmente, no Brasil, há diversas traduções bíblicas, que seguem diferentes enfoques tradutórios na

\footnotetext{
${ }^{1}$ Referência ao termo empregado por Metzenger, "exhausting”, em seu artigo sobre as dificuldades encontradas pelos tradutores da Bíblia (cf. METZGER, 1993, p. 273)

2 Por exemplo, TOV, 2012.

${ }^{3}$ Por exemplo, COHEN, 1978.

${ }^{4}$ Por exemplo, KHAN, 2013.

5 Por exemplo, STEFANINK, e BĂLĂCESCU, 2017, p. 21-52. Para o caso da tradução da Bíblia especificamente, cf. GALLOIS, 2012, p. 63-82.

${ }^{6}$ Por exemplo, SHEAD, 1993, p. 273.
} 
produção do discurso" ", chama atenção, naquelas versões, problemas de tradução de palavras e expressões de absoluta trivialidade sintático-gramatical, que nem de longe lembram os "textos dificílimos do hebraico" que se diz que Teresa de Baviera teria visto o imperador D. Pedro II traduzir ${ }^{8}$.

Em algumas passagens analisadas, o conjunto das versões revela problemas que não se esperariam, uma vez que o texto em análise não apresenta qualquer dificuldade de tradução. Algumas das passagens em que tais problemas de tradução se verificam são tão simples de traduzir que podem mesmo ser utilizadas em exercícios de fixação em classes instrumentais de hebraico bíblico. Não se trata de variantes complicadas, de termos raros, de problemas de vocalização ou de especiais propriedades semânticas de uma das línguas. A palavra a ser traduzida é simples, e, todavia, a tradução revela problemas que implicariam em má avaliação naquela referida classe instrumental. Por "problemas", quer-se indicar para o que Aulen chamou, por exemplo, de "omissão" de "erro" ${ }^{10}$. E, dado que não se trata de um problema de uma ou outra versão, mas do conjunto, resulta necessário concluir que, nesse caso, se está diante de um fenômeno e de procedimento não fortuitos. O que isso significa?

No presente artigo, é apenas desse tipo de "dificuldade" que se tratará. Nesse exercício, e com o objetivo único de comparar-lhes as operações de tradução, dez versões vernaculares da Bíblia Hebraica $^{11}$ foram selecionadas e avaliadas, confrontando-as umas com as outras, bem como com o próprio texto hebraico que traduzem,

\footnotetext{
${ }^{7}$ NEVES e LOPES, 2016, p. 213.

${ }^{8}$ Cf. ROMANELLI, MAFRA e SOUZA, 2002, p. 103-104.

9 "As omissões podem ocorrer por muitos motivos, desde censuras até [...]" (AUBERT, 1998, p. 105).

10 "Somente os casos evidentes de 'gato por lebre' incluem-se nessa modalidade" (idem, p. 109).

${ }^{11}$ A rigor, Antigo Testamento, já que, dentre as citadas, há versões que são traduções da tradução francesa, como a BJ e a TEB. Logo, não são de fato traduções da Bíblia Hebraica, mas do Antigo Testamento, por sua vez já traduzido.
} 
além de, naturalmente, com a tradução do autor ${ }^{12}$. No corpo do artigo, as versões serão indicadas pelas seguintes e respectivas siglas: AM (Ave Maria) $)^{13}$, NBP (Nova Bíblia Pastoral) ${ }^{14}, \mathrm{CNBB}^{15}$, BJ (Bíblia de Jerusalém) ${ }^{16}$, BP (Bíblia do Peregrino) ${ }^{17}$, MD (Mensagem de Deus) ${ }^{18}$, TEB (Tradução ecumênica da Bíblia) ${ }^{19}$, ARA (Almeida, revista e atualizada) ${ }^{20}$, ARE (Almeida, Melhores Textos) ${ }^{21}$ e NVI (Nova Versão Internacional) ${ }^{22}$. Serão analisadas quatro passagens traduzidas: $1 \mathrm{Re} 22,21$ e Sl 53,3.5.723. O objetivo é verificar o comportamento geral das versões brasileiras da Bíblia. O espaço imposto pelos periódicos nacionais impede que uma quantidade maior de passagens seja avaliada, salvo se se primar por quantidade, ao preço de uma avaliação menos detalhada, o que não se preferiu neste caso. Obviamente, trata-se de um retrato, válido (salvo melhor juízo) para os casos analisados. Outros exercícios deverão ser feitos, a fim de verificar se as análises abaixo apresentadas em relação aos quatro casos em tela são fortuitos ou se aplicam também a outras passagens, revelando-se um padrão.

\footnotetext{
${ }^{12}$ A tradução se faz a partir do texto publicado pela Sociedade Bíblia da Alemanha: BIBLIA HEBRAICA STUTTGARTENSIA., 1990. Procurou-se traduzir o mais literalmente possível o texto hebraico. Para as questões envolvidas, cf. AUBERT, 1998, p. 99-128; GUEDES, RODRIGUES, e MOZZILLO, 2017, p. 80-100.

${ }^{13}$ BÍBLIA SAGRADA, 2017.

${ }^{14}$ NOVA BÍBLIA PASTORAL, 2014.

${ }^{15}$ BÍBLIA SAGRADA, 2001.

${ }^{16}$ A BÍBLIA DE JERUSALÉM, 1985.

${ }^{17}$ BÍBLIA DO PEREGRINO, 2002.

${ }^{18}$ BÍBLIA, 1989.

${ }^{19}$ BÍBLIA, 1995.

${ }^{20}$ A BÍBLIA SAGRADA, 1993.

${ }^{21}$ A BÍBLIA SAGRADA, 2000.

${ }^{22}$ BÍBLIA SAGRADA, 2000.

${ }^{23}$ Para o procedimento de análise de "termos isolados" de traduções, cf. AUBERT, 1998, p. 121-125.
} 


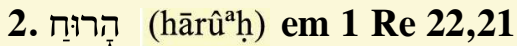

Nas versões analisadas, as traduções de 1 Re 22,21 são as seguintes:

Quadro 1 - 1 Re 22,21 em versões brasileiras da Bíblia

\begin{tabular}{|c|c|}
\hline $\mathrm{AM}$ & $\begin{array}{l}\text { "Então, um espírito adiantou-se e apresentou-se diante do Senhor, } \\
\text { dizendo: 'Eu irei seduzi-lo'". }\end{array}$ \\
\hline NBP & $\begin{array}{l}\text { "Foi então que um espírito se aproximou, colocou-se diante de Javé } \\
\text { e disse: 'Eu irei seduzi-lo"”. }\end{array}$ \\
\hline CNBB & $\begin{array}{l}\text { "Veio então um espírito e apresentou-se diante do Senhor, dizendo: } \\
\text { 'Eu o enganarei'". }\end{array}$ \\
\hline BJ & $\begin{array}{l}\text { "Então } o \text { Espírito se aproximou e colocou-se diante de Iahweh: 'Sou } \\
\text { eu que o enganarei'". }\end{array}$ \\
\hline $\mathrm{BP}$ & $\begin{array}{l}\text { "Foi então que um espírito se aproximou, colocou-se diante de Javé } \\
\text { e disse: 'Eu irei seduzi-lo"”. }\end{array}$ \\
\hline MD & $\begin{array}{l}\text { “Apresentando-se, então, } o \text { Espírito, e inclinando-se perante Javé, } \\
\text { declarou: 'Eu o induzirei'”. }\end{array}$ \\
\hline TEB & $\begin{array}{l}\text { "Então um espírito adiantou-se, apresentou-se diante do Senhor e } \\
\text { disse: 'Eu o seduzirei"”. }\end{array}$ \\
\hline ARA & $\begin{array}{l}\text { "Então, saiu um espírito, e se apresentou diante do Senhor, e disse: } \\
\text { Eu o enganarei". }\end{array}$ \\
\hline ARE & $\begin{array}{l}\text { "Então saiu um espírito, apresentou-se diante do Senhor, e disse: } \\
\text { Eu o induzirei". }\end{array}$ \\
\hline NVI & $\begin{array}{l}\text { "Até que, finalmente, um espírito colocou-se diante do Senhor e } \\
\text { disse: 'Eu o enganarei"”. }\end{array}$ \\
\hline
\end{tabular}

Fonte: o autor.

Todas as versões analisadas traduzem רֵּ (rûah como "espírito" 24 . Eventual divergência entre as versões não se dá, porf tanto, em relação ao sentido que aplicam ao termo hebraico חֵּ.

${ }^{24}$ Não se discutirá o sentido do termo hebraico. Quanto a isso, cf. KOEHLER e BAUMGARTNER, 1996. p. 1197-1201; ALONSO-SCHÖKEL, 1997. p. 609610. Ambos os dicionários atestam o sentido de "espírito" para חָ . 
O que ocorre é que, quando atualizam a expressão hebraica הָרוּ (hārûạ) que ocorre em 1 Re 22,21, em suas respectivas traduções, no conjunto, as versões oferecem duas traduções: a majoritária no vernáculo, "um espírito", com artigo indefinido e inicial minúscula, e a minoritária, "o Espírito", com artigo definido e inicial maiúscula.

Uma rápida avaliação nas traduções do quadro acima revela que apenas duas das versões traduzem a expressão hebraica הָּרוּ levando em conta a presença do artigo definido. São a BJ (“o Espírito”) e a MD ("o Espírito"). Todas as demais desconsideram a presença do artigo definido no texto bíblico que traduzem. Quando traduzem הָרוּח , substituem o artigo definido presente na expressão pelo artigo indefinido "um", atualizando-a como "um espírito".

Em termos de morfologia e sintaxe, deve-se assumir que, no contexto da frase, uma palavra em hebraico, sem artigo definido, pode ser traduzida igualmente sem artigo definido, com artigo indefinido ou até mesmo com artigo definido ${ }^{25}$. Assim, considerando-se que o sentido seja "espírito", dependendo do contexto da frase, רוּ pode ser traduzido por "espírito", "um espírito" ou "o espírito". Nesse caso, a língua em que se o traduz sobrepõe-se ao hebraico e determina, sintaticamente falando, qual das três formas alternativas encaixa-se melhor na tradução ${ }^{26}$.

Quando, todavia, um termo hebraico vem acompanhado do artigo definido, sua supressão ou sua transformação em artigo indefinido resulta irregular. Também em hebraico, o artigo definido determina, especifica determinada grandeza, representada nesse caso pela palavra a que aquele se agrega, na forma de prefixo.

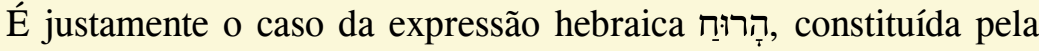
prefixação do artigo רָז רo termo Uma vez que se decide pela tradução de רִּ por "espírito", então resulta imperativo que se traduza הָרוּ por "o espírito".

${ }^{25}$ Cf. BARR, 1989, p. 307-335.

${ }^{26}$ Para as questões técnicas relativas à gramática e à sintaxe do hebraico bíblico, cf. VAN DER MERWE, NAUDÉ e KROEZE, 1999. 
Conclui-se, portanto, que todas as versões que, em $1 \mathrm{Re}$ 22,21, traduzem הָרוּ como "um espírito" devem, no mínimo, explicações quanto ao procedimento. Aqui, talvez só se possa sugerir uma hipótese explicativa: pressões teológicas. Para justificar a hipótese explicativa, é preciso recuperar, de um lado, a narrativa em que o verso está inserido, e, de outro, as implicações teológicas da passagem, quando eventualmente lida no contexto cristão brasileiro contemporâneo, ambiente em que operam os tradutores das versões analisadas.

1 Re 22,1-40 narra o episódio tradicional da morte de Acabe, rei de Israel, que se dá durante uma excursão de ataque à cidade de Ramote de Gileade (v. 35), acompanhado de seu colega de Judá, Josafá ${ }^{27}$. A narrativa é bem detalhada. Durante a visita de Josafá ao colega israelita (v. 1-3), este o convida para um ataque à cidade acima referida (v. 3-4). O rei judaíta sugere que se consultem os profetas (v. 5), que são então reunidos por Acabe, e findam por endossar o desejo do rei (v. 6.10-12). Provavelmente porque sabia como funcionam essas questões de "consulta do rei a Yahweh", e, no fim das contas, porque os profetas de cá são como os de lá, Josafá questiona se não há outro profeta que não tenha sido ouvido (v. 7), e, informando que sim, há um profeta, de nome Micaías, Acabe manda que seja chamado (v. 8-9). Encontrando-o, o encarregado de buscar o oráculo ausente adverte-o de que todos os demais profetas estão unanimemente declarando que Yahweh dará a vitória ao rei, e que ele deve fazer a mesma coisa (v. 13). Micaías diz consentir (v. 14), de sorte que, instado pelo rei, talvez sarcasticamente ${ }^{28}$, repete o discurso favorável já anunciado pelos colegas de ofício (v. 15). O monarca adverte-o de que fale a verdade (v. 16), com o que, então, modificando totalmente o que tanto os profetas quanto ele mesmo haviam dito, Micaías anuncia a derrota e morte do monarca (v. 17). Diante disso, Acabe se dirige ao colega do sul, e diz-lhe que não era de se esperar nada diferente, já que Micaías só profetizava o que fosse de encontro aos seus interesses de regente (v. 18).

${ }^{27}$ Cf. LINVILLE, 1998, p. 185-186.

${ }^{28}$ Cf. LAFFEY, 1999, p. 284. 
É nesse contexto que se insere a expressão hebraica analisada. Uma vez que Acabe desdenha de seu anúncio, Micaías passa a descrever, em chave figurativa, a cena oracular que se desenrolava diante de todos: os profetas do rei anunciando sua vitória, e apenas ele anunciando sua derrota (v. 19-23). Micaías diz que vê Yahweh sentado em seu trono celeste, ladeado pelos seus oficiais (v. 19). Yahweh se lhes dirige, inquirindo-os sobre quem dentre eles haveria de enganar o rei (para que, crendo obter a vitória, atacasse Ramote de Gileade e, ao fazê-lo, encontrasse a morte) (v. 20). Dentre eles, ninguém se apresentou (v. 20). Então, como quer o texto hebraico, הָרוּח se aproxima de Yahweh e se apresenta para a tarefa: "eu o enganarei" (v. 21). "Como?", quer saber Yahweh, ao que הָרוּ responde que "eu serei um espírito de menti-

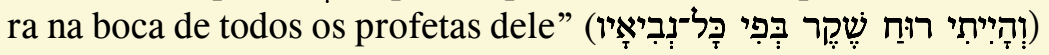
(v. 21). Micaías interpreta a cena oracular diante dele e do rei como, a serviço do deus, a ação do "espírito de Yahweh", fazendo os profetas mentirem ao rei, para, enganando-o, levá-lo à morte (v. 23). Imediatamente um dos homens do rei esbofeteia Micaías, e ensaia interditar-lhe a prerrogativa oracular em nome

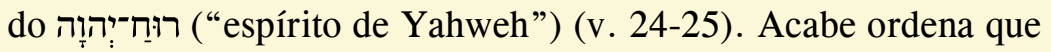
prendam o profeta até seu retorno (v. 26-27), ao que Micaías responde que, se o rei voltar, Yahweh então não teria falado por ele (v. 28). E o rei não voltou...

A narrativa contém elementos que servem de indício para a plausível hipótese explicativa quanto ao fato de, nas traduções, a maioria das versões costumeiramente substituírem o artigo definido de הָרוּ pelo artigo indefinido "um". Como se disse, tratar-se-ia de uma questão teológica, que se pode compreender por meio de alguns passos de raciocínio. Na tradição teológica cristã, กָּ foi interpretado como a Terceira Pessoa da Trindade. O tratamento teológico da passagem constrange-se de ver o assim interpretado Espírito Santo fazendo profetas mentirem, para que, crendo nas mentiras, o rei fosse morto. Se, raciocinando ao modo das catequeses, "Deus não é homem para que minta" $(\mathrm{Nm} 23,19)$, então 
o "Espírito Santo" não pode mentir ${ }^{29}$. Óbvio que se trata de uma operação de interpretação totalmente desconectada da seriedade exegética, mas é nesses termos que, com raríssimas exceções, opera o conjunto das reflexões teológicas, amiúde as de caráter mais comercial, caso em que se enquadra o mercado de Bíblias. Logo, já que, sendo "Deus", o Espírito Santo não pode mentir, e dado que, no texto, הרוּ faz o papel de "espírito de mentira" ${ }^{30}$ na boca dos profetas do rei, então esse não pode ser "o" Espírito Santo. Já que é um espírito, então tem de ser outro espírito. Todavia, o hebraico traz הרוּח ("o espírito"). Entretanto, se, como deve, o tradutor traduz הָרוּ como "o espírito", corre-se o risco de o piedoso leitor das Escrituras sensibilizar-se, das duas uma, ou com o que ele pode interpretar como desrespeito com o "espírito", escrito com $e$ minúsculo, ou com o que ele pode experimentar como escândalo, dado o fato de "o Espírito Santo" mentir e fazer mentir ${ }^{31}$. Resta, pois, uma alternativa à maioria dos tradutores da passagem: eliminar o artigo definido, traduzir, ainda que equivocadamente, הרוּח como "um espírito" e deixar que os leitores interpretem tratar-se, então, de um daqueles espíritos costumeiramente presentes nas narrativas do Novo Testamento, e que constituem não os "exércitos de Deus", mas os "exércitos do diabo" 32 . De qualquer forma, todo esforço deve ser feito para contornar o risco de interpretar-se a passagem como se referindo ao Espírito Santo.

${ }^{29}$ Para esse tipo de raciocínio teológico, cf. HARRIS, 2005, p. 79-81.

${ }^{30}$ Para uma aproximação à história da pesquisa sobre o "espírito de mentira" em $1 \mathrm{Re}$ 22,22, cf. MAYHUE, 1993, p. 135-163. Adverte-se, todavia, que o final da pesquisa é a conclusão de que o "espírito de mentira" de que fala a passagem é Satã" (p. 162).

${ }^{31}$ Se a avaliação estiver correta, trata-se de uma preocupação muito específica com o leitor da versão brasileira, já que há quem assuma que mesmo se traduzindo "o espírito", e não "um espírito" ainda assim se trate de um "ser divino [...] como

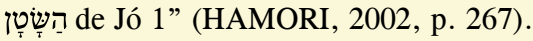

32 É exatamente o que sugere a seguinte observação, constante em um comentário ao texto de 1 Reis, que, a despeito de autoria internacional, circula no mercado nacional: "para garantir que Acab não ouça a profecia de sua morte e se liberte, Miquéias diz que o Senhor até permitiu um espírito de mentira na boca dos profetas" (LAFFEY, 1999, p. 284). 
É possível entrever o raciocínio que se acaba de apresentar, caso se recorra às próprias versões. Na nota b à $1 \operatorname{Re} 22,21$, a TEB informa ao leitor que "alguns compreendem que esse espírito é um dos membros da corte celeste mencionada no v. 19. Outros veem nela o espírito de Deus que se manifesta ao profeta. Não é ainda o Espírito Santo de que fala o NT". Em termos exegéticos, mas não necessariamente em termos teológicos, é óbvio que não se trata do "Espírito Santo de que fala o NT". Nisso o comentarista está correto. O que não se explica, todavia, é por que, sabendo disso, tenha traduzido "um espírito", já que deveria, necessariamente, ter traduzido "o espírito". Seja como for, a nota citada serve de indício de que a questão da interpretação do "Espírito Santo de que fala o NT" seja o ponto crucial dessa tradução, que deve explicações.

Seguindo a mesma linha de raciocínio, é possível entrever um comportamento ainda mais acintoso por parte da NVI. Se colocada ao lado da MD, então, o comportamento da NVI revela-se carregado de aparente propósito: ocultar do texto qualquer elemento que possa "induzir" o leitor a entrever referência ao Espírito Santo. Como se viu, no v. 21 de 1 Re 22, a MD traduz הָרוּ como "o Espírito", ao passo que a NVI, "um espírito". Mais adiante, no v. 24, o texto hebraico emprega a expressão רוּחָ־יָהוֹ ("espírito de Yahweh" ou "o espírito de Yahweh"). A MD, que havia traduzido רזרוּח como "espírito de Javé". Já a NVI, uma vez que traduzira הָרוּר como "um espírito", aparentemente, para impossibilitar qualquer referência ao "Espírito

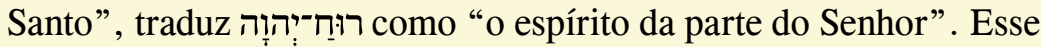
caso é bastante revelador das operações subreptícias que parecem envolver tais procedimentos de tradução.

Como se viu, ao lado de outras versões, em 1 Re 22,21, a NVI descaracteriza a identidade do agente da corte divina, desprezando o artigo definido e traduzindo הָרוּ como "um espírito". Mas é no v. 24 que, ao manejar a pena, a mão teológica parece se revelar mais indisfarçadamente. Na passagem, o homem do rei ataca Micaías, que havia acabado de arrogar a si a inspiração profética, e o questiona, perguntando como podia pretender que o "espírito de 


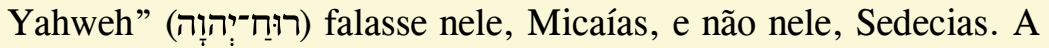

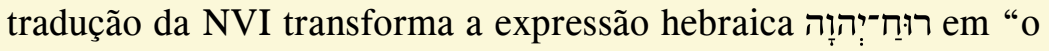
espírito da parte do Senhor”. Inserida no v. 24 , uma nota $a$ constrangidamente ressalva: "ou o Espírito do". O tradutor sabe que

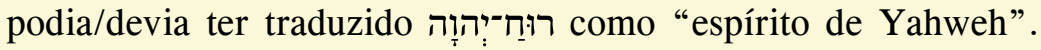
Mas parece que ele não pode. Está-se ou não diante de uma tradução controlada por motivação teológica, no sentido de evitar sugerir que, identificado na referência, o "Espírito Santo" esteja vinculado à mentira? Determinada pelo artigo definido, no v. 24, a tradução “o espírito da parte de Yahweh" remete àquele assim tratado como indefinido espírito, do v. 21. Com uma operação de "tradução", teologicamente controlada, a NVI oculta a referência ao "espírito de Javé". O fato de que, a despeito de, no v. 21, terem se comportado exatamente como a NVI, nenhuma das outras versões que aí traduzem "um espírito" atualizam a expressão רוּחַ־יִיהוֹה do v. 24 da mesma forma como a traduz a NVI. O procedimento que levam a termo no v. 21, não é repetido no v. 24.

Por outro lado, para o caso estudado, as tradução da BJ mantém-se mais próxima do texto hebraico: "então $o$ Espírito se aproximou e colocou-se diante de Iahweh: 'Sou eu que o enganarei'". A tradução de הָרוּ como "o Espírito" é quase que literal. Não o é, em termos absolutos, por força do uso da maiúscula em "Espírito", o que se dá, evidentemente, apenas por questões teológicas. Isso não tira o mérito da tradução. Em todo caso, é na nota d, de 1 Re 22,21, que a BJ dissipa qualquer dúvida que se pudesse ter sobre a interpretação que o tradutor ou o comentarista faz da passagem, quando traduz "o Espírito": "personificação do espírito profético, que o desígnio divino transformará em espírito de mentira". Nenhum escrúpulo teológico a censurar a literalidade da tradução e a abordagem histórico-social da interpretação, que, quanto a essa passagem, marca a NVI. Aqui estamos em território propriamente exegético, de sorte que, ao menos nesse caso, resultados próprios da história dos efeitos da narrativa não são operados retroativamente, de sorte a determinar censuras e ocultamentos no nível narrativo. 


\section{Três problemas de tradução em Sl 53,3.5.7}

S1 53 é um salmo fascinante. Quem o compôs é mestre poeta, artífice escritor, mágico retórico, e, não bastasse isso, um analista político-social invejável. Tenho dificuldades em aceitar que o Sl 53 seja a versão "secundária" do Sl $14^{33}$. Trata-se do mesmo salmo, obviamente, mas quero crer que o S1 53 seja o original. Ao menos uma regra da hermenêutica de textos antigos autoriza a declaração: textos "mais difíceis" são, em tese, mais antigos do que suas versões "mais fáceis" de ler e entender ${ }^{34}$. Nesse caso, o v. $6^{35}$ é quase que completamente diferente nos dois salmos, o que resulta necessário concluir que o problema que teria gerado a duplicação da composição original fora justamente esse verso. Pois bem, Sl 53,6 não é de difícil tradução, mas, ao mesmo tempo, não é de fácil interpretação. Já quanto à seção correspondente do Sl 14, nesse caso, Sl 14,5-6, nem a tradução nem a interpretação são particularmente difíceis, tendo sido substancialmente descaracterizado o conteúdo político

33 Refiro-me à opinião de Alonso-Schökel e Carniti, que consideram o Sl 53 secundário em relação ao Sl 14, e ainda o dão por estado de conservação pior do que o 14 (ALONSO-SCHÖKEL e CARNITI, 1996, p. 249-261 e p. 717-718). Essa é igualmente a posição de Kraus (2009, p. 337-348) e de Weiser (1994, p. 115-117). Alonso-Schökel e Carniti ainda reservam algumas páginas para o comentário em separado do Sl 53, mas Kraus e Weiser parecem tão seguros da condição secundária, logo, “inferior”, do Sl 53, que não apresentam comentários à parte, fazendo-o apenas para o Sl 14. A despeito da autoridade dos autores citados, insista-se na regra hermenêutica.

${ }^{34}$ Note-se que, considerando o S1 53 uma segunda transmissão, com variantes, do Sl 14, o próprio Kraus acrescenta que "a forma do texto no Sl 53 (especialmente em 53,6) é mais complicada e menos transparente que no Sl 14" (KRAUS, 2008, p. 341). Quanto à regra mencionada, trata-se do princípio lectio difficilior potior, segundo o qual, se há duas versões de um mesmo texto, e uma delas impõe ao leitor uma leitura "mais difícil”, provavelmente esta é a versão original, e a de leitura "mais fácil”, a variante (TREBOLLE BARRERA, 1999, p. 452). Tanto Kraus quanto Alonso-Schökel e Carniti não aplicaram a regra ao caso.

${ }^{35}$ No hebraico; nas versões evangélicas, o v. 5. Além disso, ao v. 6 do S1 53, correspondem os v. 5-6 do Sl 14. Kraus deposita justamente nesse verso a razão de sua impressão quanto à má preservação do Sl 53 (cf. KRAUS, 2008, p. 341). A despeito da autoridade do autor, não há razão objetiva para se considerar assim. 
do verso (original) do S1 $53^{36}$. Nesse caso, nos termos da regra citada, é mais adequado considerar que o Sl 53 seja o original e, por conta de problemas que se evidenciam particularmente no v. 6, talvez justamente problemas políticos, uma versão "corrigida" tenha sido elaborada, eventualmente para substituir a anterior, resultando, contudo, que as duas versões ${ }^{37}$ tenham sobrevivido ao tempo e tenham findado compondo o mesmo conjunto de textos sagrados.

A despeito de o principal problema de tradução do S1 53 localizar-se no v. 6, este não é o único verso em que as traduções deixam a desejar. No presente exercício, serão analisados problemas específicos apenas dos v. 3, 5 e $7^{38}$, apresentados sinteticamente no quadro abaixo:

\section{Quadro 2 - Problemas pontuais de tradução do Sl 53,3.5.7}

\begin{tabular}{|c|c|}
\hline AM & $\begin{array}{l}\text { "Filhos dos homens" (v. 3), "eles, que devoram meu povo como quem } \\
\text { come pão" (v. 5) e "Ah, que venha de Sião a Salvação de Israel" (v. 7). }\end{array}$ \\
\hline NBP & $\begin{array}{l}\text { "Filhos dos homens" (v. 3), “devoram o meu povo como se estivessem } \\
\text { comendo pão" (v. 5) e "Ah, que venha de Sião a salvação de Israel!" (v. } \\
\text { 7). }\end{array}$ \\
\hline CNBB & $\begin{array}{l}\text { "Os homens" (v. 3), "devoram meu povo como se fosse pão" (v. 5) e } \\
\text { "quem mandará de Sião a salvação de Israel?". }\end{array}$ \\
\hline BJ & $\begin{array}{l}\text { “Os filhos de Adão" (v. 3), "devoram o meu povo como se comessem } \\
\text { pão" (v. 5) e "quem trará de Sião a vitória para Israel?" (v. 7). }\end{array}$ \\
\hline BP & $\begin{array}{l}\text { "Os filhos de Adão" (v. 2), "devoram meu povo como quem come pão" } \\
\text { (v. 4), "oxalá venha de Sião a salvação de Israel” (v. 7). }\end{array}$ \\
\hline
\end{tabular}

${ }^{36} \mathrm{Cf}$. a nota h do Sl 53,6 na TEB: "diversamente do Sl 14,5-6, este verso se dirige a um representante da cidade" (BÍBLIA. Tradução ecumênica).

${ }^{37}$ Ainda que muito brevemente, Alonso-Schökel e Carniti ensaiam uma tentativa de explicação tanto do contexto específico do Sl 53, quanto da preservação de duas variantes. A circunstanciação redacional do Sl 53 em relação ao cerco de Jerusalém por Senaqueribe, cerca de 701 a.C., parecem adequadas (cf. ALONSO-SCHÖKEL; CARNITI, 1996, p. 718).

${ }^{38}$ A tradução do $\mathrm{Sl}$ 53,6 das versões analisadas é objeto de artigo específico submetido ao dossiê "Bíblia e Violências" (2018/1) da revista Unitas, do Programa de Mestrado Profissional em Ciências das Religiões, da Faculdade Unida de Vitória, ainda não publicado. 


\begin{tabular}{|c|c|}
\hline MD & $\begin{array}{l}\text { "Aos filhos dos homens" (v. 3), "que estão a engolir o meu povo? É } \\
\text { o meu povo o pão que comem" (v. 5) e "que de Sião venha logo a } \\
\text { salvação de Israel!" (v. 7) }\end{array}$ \\
\hline TEB & $\begin{array}{l}\text { "Os homens" (v. 3), "que devoram o meu povo ao comer seu pão" (v. } \\
\text { 5), "quem, desde Sião, dá vitórias a Israel?" (v. 7). }\end{array}$ \\
\hline ARA & $\begin{array}{l}\text { "Filhos dos homens" (v. 2), "esses, que devoram meu povo como quem } \\
\text { come pão?" (v. 4) e "quem me dera que de Sião viesse já o livramento } \\
\text { de Israel" (v. 6). }\end{array}$ \\
\hline ARE & $\begin{array}{l}\text { "Filhos dos homens" (. 2), "os quais comem o meu povo como se } \\
\text { comessem pão" (v. 4) e "Oxalá que de Sião viesse a salvação de } \\
\text { Israel!" (v. 6). }\end{array}$ \\
\hline NVI & $\begin{array}{l}\text { "Filhos dos homens" (v. 2), "eles devoram o meu povo como quem } \\
\text { come pão" (v. 4) e "Ah, se de Sião viesse a salvação para Israel!" (v. } \\
\text { 6). }\end{array}$ \\
\hline
\end{tabular}

Fonte: 0 autor.

\subsection{Os אִּ̣ (bonê 'ādāām) em Sl 53,3}

Sl 53,3 descreve a seguinte cena: como que de alguma amurada ou sacada ${ }^{39}$, desde seu templo celeste, Yahweh debruça-se para ob-

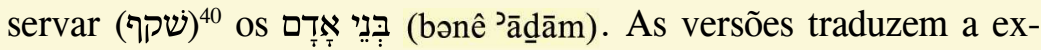

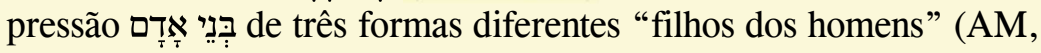
NBP, MD, ARA, ARE, NVI), "homens" (CNBB, TEB), "filhos de Adão" (BJ, BP). É possível que a tradução "homens", da CNBB e da TEB, constitua meramente simplicação da expressão que a maioria das versões analisadas usa na tradução: "filhos dos homens". "Filhos dos homens" é a forma como Kraus igualmente traduz a ex-

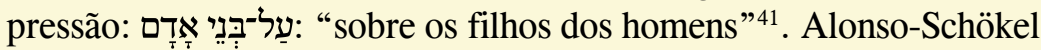
e Carniti tratam-nos como "os descendentes de Adão"42, e Weiser

\footnotetext{
39 "O Senhor assoma do céu, como a um balcão de sua morada sublime" (ALONSO-SCHÖKEL; CARNITI, 1996, p. 256).

${ }^{40}$ Para o uso de שקף para descrever Yahweh observando atentamente desde seu templo celeste, cf. Dt 26,15; S1 85,11; 102,20; Lm 3,50. Kraus fala de "mirada escrutadora de Dios” “mirada perscrutadora de Deus” (KRAUS, 2009, p. 344).

41 "Sobre los hijos de los hombres" (KRAUS, 2009, p. 344).

${ }^{42}$ ALONSO-SCHÖKEL; CARNITI, 1996, p. 256.
} 
se refere a eles como os homens da "Terra" ${ }^{43}$. No conjunto, Kraus, Weiser e Alonso-Schökel e Carniti endossam as traduções analisadas: "filhos dos homens", "homens" e "filhos de Adão". No entanto, a despeito da unanimidade, há dois problemas de difícil contorno.

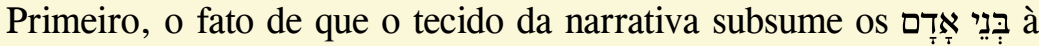

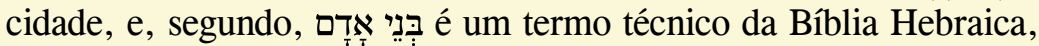
e designa uma categoria muito específica de pessoas.

Quanto ao tecido narrativo, para não dizer impossível, diga-se que é difícil a defesa de בִּנֵי אָדָם como "os homens em geral”, da “Terra”, "os descendentes de Adão". Resumidamente, o raciocínio é o seguinte. Na narrativa, diz-se que, cotidianamente, os בִּנֶּנ

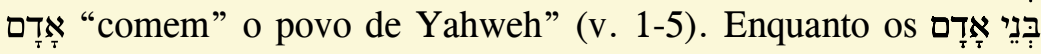
estão envolvidos na atividade de "comer o povo", em certa ocasião, sua cidade é sitiada por um exército (v. 6). O texto fala, portanto, de três grupos diferentes: dentro da cidade, a) os ơ e b) aqueles que a divindade trata de "meu povo", e, fora da cidade, c) o exército sitiador. O texto não permite que בִּנִי אָדָָ seja interpretado como designando o conjunto dos homens em geral, a população da "Terra", "os descendentes de Adão", a "humanidade". Tratar

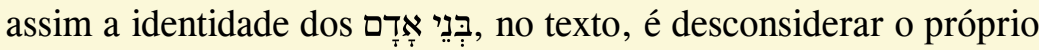

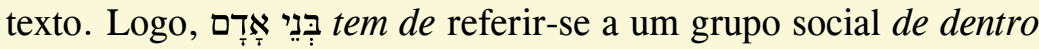
da cidade. Mais ainda: se trata de um grupo social, de dentro da cidade, que "devora" o "povo de Yahweh", que igualmente se encontra dentro da cidade.

A questão se resolve, quando se assume que בִּנִי אָדָ é um termo técnico da Bíblia Hebraica ${ }^{44}$ : "a identidade dos bənê 'ādām como corpo governamental pode ser revelada nas seguintes passagens: Dt 32,8; 2 Sm 7,14; Sl 21,11; 36,8; 45,3; 53,3 = 14,2; 58,2 e 89,

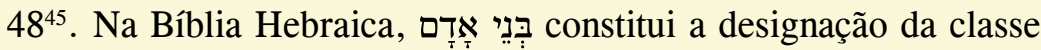
social dominante, constituída pelo rei e pelo aparelho de governo, incluídos todos os operadores governamentais, do rei ao eunuco da corte. Não é por outra razão que o Sl 53 descreve apenas dois

${ }^{43}$ Cf. WEISER, 1994, p. 116.

${ }^{44}$ Cf. RIBEIRO, 2011, p. 145-161.

${ }^{45}$ Idem, p. 157. 


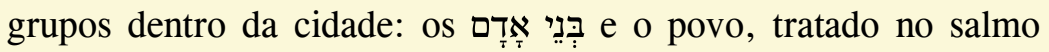

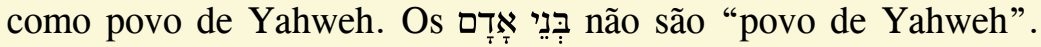
São encarregados de Yahweh para o cuidado do povo. Essa é a razão da precisa ironia com que são tratados no v. 5: "obreiros da injustiça”. Nos termos da demagogia real, os אָָָּּ foram colocados no poder pela divindade, para protegerem o povo. No entanto, em lugar de protegê-lo, "devoram-no". Logo, se, como eles mesmos dizem ser, são obreiros, são-no então da injustiça, não da justiça. No salmo, portanto, a divindade não se debruça sobre "os homens", sobre a "humanidade", sobre os habitantes da "Terra". Debruça-se sobre a classe dominante, e apenas sobre ela, para ver se, nela, há alguém que faça o que deve fazer. As versões equivocam-se, quando traduzem a expressão por "filhos dos homens" e "homens", e o fato de serem homologadas pelos autores citados não modifica a situação, porque também sua avaliação precisa ser corrigida.

\section{2 "Como (?) quem come pão" - Sl 53,5}

A TEB não se saiu bem quanto a S1 53,3, como se pode ver na análise da seção anterior. Todavia, é excepcional seu comportamento quanto a S1 53,5: "devoram o meu povo ao comer seu pão". A rigor, não é uma tradução literal das expressões hebraicas que constituem esse trecho da passagem, mas o sentido é exatamente

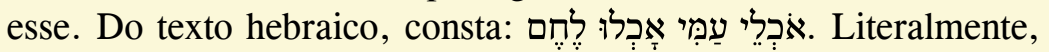
"os comedores do meu povo, eles comem pão". A TEB interpreta o conjunto de palavras e produz uma tradução que se poderia classificar como do tipo equivalência dinâmica ${ }^{46}$. Mais à frente, volta-

${ }^{46} \mathrm{O}$ portal da Sociedade Bíblica do Brasil refere-se explicitamente ao processo: "num caso como o de 1Pedro 1.13, traduções dinâmicas expressam o significado de forma direta, dispensando o processo reflexivo do leitor e garantindo que ele entenda a mensagem de forma imediata e correta. Uma tradução de equivalência dinâmica como A Bíblia para Todos (Portugal, 2009) diz, em 1Pe 1.13: "tenham o espírito preparado para a ação". A Nova Tradução na Linguagem de Hoje, entendendo que o espírito ou a mente não age sem a pessoa, diz de forma direta: 
mos ao caso. Convém, antes, comentar o resultado das atualizações das demais versões analisadas.

Dentre as dez, nove (AM, NBP, CNBB, BJ, BP, ARA, ARE e NVI) recorrem ao recurso de inserir uma cláusula de comparação אָכִלי עַמִּי אָכְלוּ לֶֶֶם produzindo algo mais ou menos como "eles devoram o meu povo como se comessem pão". Ainda que igualmente empregue a cláusula comparativa, a CNBB chega a entrever associação metafórica entre "povo" e "pão": "devoram meu povo como se fosse pão", distanciando-se ainda mais da literalidade da fórmula hebraica. Não é diferente, pelo contrário, é ainda mais agudamente distante da tradução palavra por palavra do hebraico, a tradução da MD: "estão a engolir o meu povo? É o meu povo o pão que comem".

No juízo do pesquisador, palavra a palavra, a fórmula hebraica

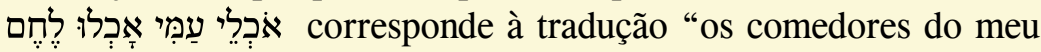
povo, eles comem pão". O verbo אכל אל é empregado duas vezes no verso: "os comedores" e "eles comem". No primeiro caso, trata-se de um particípio construto (אָכְלִי), que, em associação com um subs-

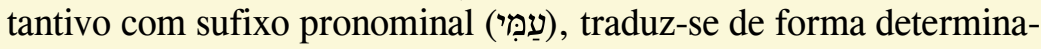
da: "os comedores do meu povo". No segundo caso, trata-se de um completo de Qal (אְָָָ), associado a um objeto direto (לֶ) :eles comem pão". A interpretação da TEB constrói-se com a redução de infinitivo da relação subordinativa entre as duas orações: "devoram o meu povo ao comer seu pão". Ou seja, "ao comer pão, eles devoram o meu povo", ou "é comendo pão que eles comem o meu povo". A TEB está correta, e o que o texto hebraico sugere é que se trata de uma violência intrínseca ao sistema econômico da cidade.

Se o leitor se reportar à análise feita na seção anterior, recuperará a informação de que, na cidade, o salmista identifica dois grupos na cidade: os bənê 'ādām e o povo. Os bənê 'ādām são chamados de "obreiros da injustiça" e de "comedores do meu povo". Já o povo é chamado de "o meu povo", isto é, é tratado

“estejam prontos para agir'” (SOCIEDADE BÍBLICA DO BRASIL. 2018, grifo nosso).

Cad. Trad., Florianópolis, v. 38, n $^{0}$ 3, p. 68-92, set-dez, 2018 
pelo salmista como sendo o povo de Yahweh. Nos termos da demagogia teológica da coroa, Yahweh coloca os bənê ’ādām no poder, para que cuidem do povo. Em troca, o povo provê o sustento da coroa. Enquanto produz para si, o povo deve produzir um excedente, com o qual os bənê 'ādām são sustentados, em troca do que garante a segurança e o cuidado "pastoral" da população $0^{47}$. No salmo, os bənê 'ād̄ām são acusados de terem se corrompido (v. 2), se extraviado (v. 4), de praticarem a injustiça (v. 2), sendo por isso chamados de "obreiros da injustiça" (v. 5). Essas designações são, todavia, muito genéricas, porque não se sabe, por meio das expressões empregadas, qual seja exatamenp

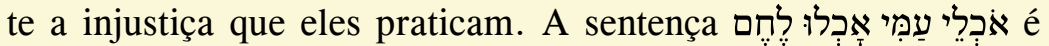
uma auerbachiana ${ }^{48}$ fórmula, concisa, portanto, de denúncia da injustiça específica que, a crer no salmista, os bənê 'ādām estão cometendo: para a manutenção da corte (os bənê 'ādām), os níveis de tributos exigidos da população estão (ao juízo do salmista) insuportáveis, levando à deterioração das condições de vida da população, do "povo do deus", de quem os bonê 'ādām deviam cuidar. Para seu sustento, a corte torna cada vez mais insustentável a vida do povo. É comendo seu pão que os bənê 'ād̄ām "comem" o povo. O salmista denuncia o mecanismo "legal" da cidade, levado às suas condições mais cínicas e deterioradas.

A despeito de não se sair bem nos demais quesitos analisados do S1 53, a ideia de que a corte devora o povo, figurativamente falando, quando impõe sobre ele um jugo tributário além de suas forças pode ser depreendida perfeitamente da tradução da TEB: "eles devoram o meu povo ao comer seu pão".

\subsection{Como assim, "salvação"? Sl 53,7}

Já havia ganho sozinha a "disputa na seção 2.2, e, de novo, a TEB vai ganhar, agora, a disputa da seção 2.3. Está em questão

${ }^{47}$ Para o modelo econômico pressuposto, cf. REIMER, 2006, p. 7-32.

${ }^{48}$ Cf. AUERBACH, 2013, p. 9. 


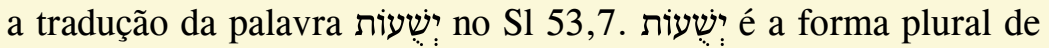
יששוּעָ , e os sentidos aplicados a ela pelas versões não estão em caus sa. Tanto "salvação", quanto "livramento" e, eventualmente, "vitória", em termos contextuais, são, todas, potencialmente viáveis. O problema se dá no número. No hebraico, a palavra se encontra no plural, não no singular, mas todas as versões analisadas, com a exceção da TEB, vertem-na no singular. Desde que o leitor compreenda que se está tratando exclusivamente do número com que o substantivo foi traduzido, e não a tradução de toda a sentença, a TEB é a única que seguiu o código de número com que o substantivo está marcado em hebraico: "quem, desde Sião, dá vitórias a Israel?". Vitórias. Teria sido melhor "salvações", mas o que importa, aqui, é que a TEB traduziu "vitórias", e não "vitória". As demais, todas, "salvação", "livramento" e "vitória".

Não se está "coando mosquitos”. Com efeito, há expressões em hebraico que são plurais, mas podem ser tranquilamente traduzidas

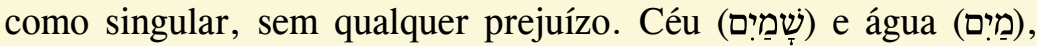
por exemplo. Os termos hebraicos são gramaticalmente duais, mas podem ser traduzidos, no mesmo contexto, na mesma passagem, tanto como "céu" e "água”, quanto como "céus" e "águas”, sem que isso altere o sentido do texto. Não é o caso, todavia, de ישוּעָ . Uma coisa é "salvação". Outra, "salvações". O texto não fala de

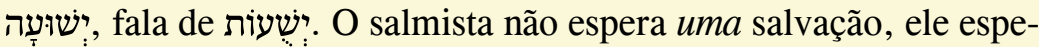
ra "salvações". Não se trata da referência, por parte do salmista, de um evento significativo, especial, específico, único, mas isso que o salmista espera constitui-se de sucessivos elementos de um processo ininterrupto, constante, repetitivo: "salvações".

No contexto do salmo, trata-se da esperança de que, ao contrário do que tem sido até aquele momento em que o salmista formula sua esperança tão fragilizada ("quem dera" (מי יתֵן)), de Sião não venham mais as injustiças e as opressões dos bənê 'ādām da mesma Sião, mas passem a vir as salvações. O salmista espera a "conversão" dos bənê 'ādām. Não está tão seguro quanto a isso, porque, se estivesse, não empregaria uma interjeição tão ambígua quanto "quem dera”, e talvez ainda fumegue nele uma pequena fumaça de esperança. 
O sentido do v. 7 está diretamente ligado ao sentido do v. 6 (e como as versões parecem ter tropeçado aqui, tropeçaram também ali). O salmo está dividido em três seções. Na primeira, v. 1-5, o salmista denuncia as opressões e as injustiças dos bənê ’ādām. São injustiças cotidianas, contínuas, incessantes. No v. 6, o salmista conta um episódio apenas aparentemente sem ligação com a história, mas que é nevrálgico na economia retórica da composição: os bənê 'ā fiança do deus da cidade, experimentaram o horror de imaginarem-se executados pelos sitiadores. O terror tomou conta de seus ossos, e essa foi uma experiência profunda. No v. 7, escrito necessariamente quando o salmista não sabe ainda que transformações o cerco teria operado, ou não, nas entranhas dos bənê 'ādām, o salmista registra sua esperança, sua dúvida, seu desejo: que a terrível experiência do cerco transforme a tal ponto os bənê 'ādām, que, "de Sião venham

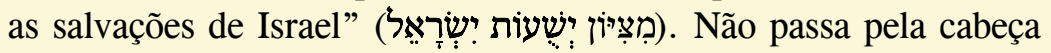
do salmista um evento miraculoso - "salvação de Israel". Se um milagre deve ser esperado, é a conversão dos bonê 'ād̄ām, e, quem sabe?, o cerco pode tê-lo operado. Mas as salvações que o salmista espera são tão triviais quanto trivial é o modo como os "comedores do meu povo" comem seu pão. O salmista espera que relações de justiça de (re)estabeleçam na cidade. Apenas isso. Quanto ao que, todavia, não parece muito confiante.

Concluo a seção com uma hipótese explicativa. A suspeita de

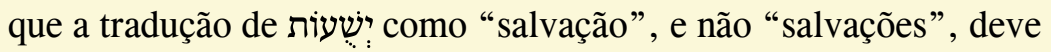
estar vinculada ao início do salmo e à interpretação do poema como uma referência ao ateísmo não deve ser descartada. Eventualmente, os tradutores operaram sobre um subtexto teológico vinculado ao contexto da tradução, e não da redação, no qual a superação do ateísmo se dá por meio daquela "salvação" com que os tradutores da Bíblia estão acostumados, dado seu exercício religioso profissional. Se essa análise estiver correta, enxergaram ateísmo onde não há ${ }^{49}$, humanidade onde não há, e salvação onde não há.

${ }^{49}$ Para a referência a "ateísmo prático" no Sl 53, cf. KRAUS, 2009, p. 344. 


\section{Conclusão}

$\mathrm{O}$ artigo selecionou dez versões brasileiras da Bíblia Hebraica ${ }^{50}$, escolheu quatro passagens pontuais $(1 \mathrm{Re} 22,21$ e $\mathrm{Sl} 53,3.5 .7)$, as traduziu ${ }^{51}$, e, em seguida, analisou as traduções reunidas. No conjunto, as versões distanciam-se substancialmente do texto hebraico e de seu sentido, seja por razões de pressão teológica, na forma concreta de operação hermenêutica por meio de subtextos teológicos, seja por não alcançarem suficientemente o sentido da passagem. Em duas ocasiões, S1 53,5.7, a TEB sai-se melhor do que as demais, traduzindo as expressões hebraicas em perfeita adequação ao sentido da passagem. A BJ se sai melhor na tradução de 1 Re 22,21. Quanto a Sl 53,3, nenhuma das traduções poderia ser defendida, conquanto, na literalidade da fórmula, a BJ e a BP ao menos não traem a expressão hebraica que traduzem.

O resultado a que se chega é que, a depender dessas versões, o leitor não especializado, sem acesso ao texto hebraico, não terá condições de entender o sentido da passagem conforme gravado na língua fonte. Grave se dá o quadro, quando se percebe que ainda que o leitor se municie com as dez versões, em uma das quatro passagens (S1 53,3), nenhuma ajuda receberá dos tradutores (com exceção, talvez, da BJ e da $\mathrm{BP}$ ), uma vez receberá ajuda para $1 \mathrm{Re}$ 22,11 (BJ), e, em ambos os casos, da TEB, receberá ajuda para Sl 53,5.7. A chance, todavia, de um leitor se municiar ao mesmo tempo das dez versões é remota. No conjunto, com as exceções muito pontuais indicadas, deve-se trabalhar com o quadro geral de que, ao menos quanto a essas passagens analisadas, o leitor terá negado seu acesso ao sentido do texto hebraico.

\footnotetext{
${ }^{50}$ Por meio de notas, individualmente identificadas na Introdução.

${ }^{51} \mathrm{O}$ autor reconhece que o mesmo tipo de análise pode ser feita com sua própria tradução e espera que, nesse quesito, se saia melhor do que as versões que analisou.
} 


\section{Referências}

ALONSO-SCHÖKEL, Luis. Dicionário bíblico hebraico-português. Tradução de Ivo Storniolo e José Bortolini. São Paulo: Paulus, 1997.

. ; CARNITI, Cecília. Salmos I. Tradução de João Rezende Costa. São Paulo: Paulus, 1996. (Salmos 1-72)

AUBERT, Francis Henrik. Modalidades de tradução: teoria e resultados. TradTerm, São Paulo, v. 5, n. 1, p. 99-128, 1998.

AUERBACH, Erich. A cicatriz de Ulisses, In: . Mimesis. A representação da realidade da literatura ocidental. 6. ed. Vários tradutores. São Paulo: Perspectiva, 2013.

BARR, James. "Determination" and the Definite Article in Biblical Hebrew. Journal of Semitic Studies, Oxford, v. 34, n. 2, p. 307-335, 1989.

COHEN, Harold R. Biblical hapax legomena in the light of Akkadian and Ugarit. Ann Arbor: Scholars Press, 1978.

GALLOIS, Dominique Tilkin. Traduções e aproximações indígenas à mensagem cristã. Cadernos de Tradução, Florianópolis, v. 2, n. 30, p. 63-82, 2012.

GUEDES, Clara Peron da Silva; RODRIGUES, Roberta Rego; MOZZILLO, Isabella. Modalidades de tradução: uma investigação do conto traduzido "Dez de Dezembro”. Cadernos de Tradução, Florianópolis, v. 37, n. 2, p. 80-100, 2017.

HAMORI, Esther J. The Spirit of Falsehood. The Catholic Biblical Quaterly, n. 72, p. 15-30, 2010.

HARRIS, Gregory H. Does God deceive? "Deluding influence" of Second Thessalonians 2:11. The Master's Seminary Journal, Winona Lake, n. 16, v. 1, p. 73-93, 2005. 
KRAUS, Hans-Joachim. Los Salmos. Tradução de Constantino Ruiz-Garrido. Salamanca: Sígueme, 2009. v. 1. (Salmos 1-59)

KHAN, Geoffrey (Ed). Encyclopedia of Hebrew Language and Linguistics. Leiden: Brill, 2013. v. 3.

KOEHLER, Ludwig; BAUMGARTNER, Walter. The Hebrew and Aramaic lexicon of the Old Testament. V. III: ש - Tradução de M. E. J. Richardson. Leiden: Brill, 1996.

LAFFEY, Alice L. 1 e 2 Reis. In: BERGANT, Diane; KARRIS, Robert J. (Orgs.). Comentário Bíblico. I. Introdução. Pentateuco. Profetas Anteriores. 3. ed. Tradução de Ivo Storniolo. São Paulo: Loyola, 1999. p. 273-292.

LINVILLE, James Richard. Israel in the Book of Kings. The Past as a Project of Social Identity. Sheffield: Sheffield Academic Press, 1998.

LONG, Jesse C. 1 \& 2 Kings. Joplin: College Press, 2002.

MAYHUE, Richard L. False prophets and the deceiving spirit. The Master's Seminary Journal, Winona Lake, n. 4, v. 2, p. 135-163, 1993.

METZGER, Bruce M. Persistent problems confronting Bible translators. Bibliotheca Sacra, Roma, n. 150, p. 273-284, 1993.

NEVES, Maria Helena de Moura; LOPES, Mariú Moreira Madureira. Texto bíblico e "tradução": a "voz divina" no plano humano da coenunciação. Cadernos de Tradução, Florianópolis, v. 36, n. 2, p. 205-236, 2016.

REIMER, Haroldo. Sobre economia do Antigo Israel e no espelho de textos da Bíblia Hebraica. In: RICHTER REIMER, Ivoni (Ed.). Economia no mundo bíblico. Enfoques sociais, históricos e teológicos. São Leopoldo: Sinodal; Cebi, 2006. p. 7-32.

RIBEIRO, Osvaldo Luiz. bonê ’ādāam. Os "filhos de Adão" na Bíblia Hebraica. Reflexus, Vitória, v. 5, n. 6, p. 145-161, 2011. 
ROMANELLI, Sergio; MAFRA, Adriano; SOUZA, Rosane. D. Pedro II tradutor. Análise do processo criativo. Cadernos de Tradução, Florianópolis, v. 2, n. 30, p. 101-118, 2002.

SHEAD, Stephen L. Radical Frame Semantics and Biblical Hebrew. Exploring Lexical Semantics. Leiden: Brill, 2012.

SOCIEDADE BÍBLICA DO BRASIL. Princípios de tradução. Disponível em: < http://www.sbb.org.br/a-biblia-sagrada/principios-de-traducao >. Acesso em: 17 jul. 2018.

STEFANINK, Bernd; BĂLĂCESCU, Ioana. The hermeneutical approach in translation studies. Cadernos de Tradução, Florianópolis, v. 37, n. 3, p. 21-52, 2017.

TOV, Emanuel. Textual Criticism of the Hebrew Bible. 3. ed. Minneapolis: Fortress Press, 2012.

TREBOLlE BARRERA, Julio. A Bíblia judaica e a Bíblia cristã. Tradução de Ramiro Mincato. 2. ed. Petrópolis: Vozes, 1999.

VAN DER MERWE, Christo H. J.; NAUDÉ, Jackie A.; KROEZE, Jan H. $A$ biblical Hebrew reference grammar. Sheffield: Sheffield Academic Press, 1999.

WEISER, Artur. Os Salmos. Tradução de Ivo Storniolo. São Paulo: Paulus, 1994.

\section{Bíblias}

NOVA BÍBLIA PASTORAL. São Paulo: Paulus, 2014.

BÍBLIA SAGRADA. Tradução da CNBB, com introduções e notas. São Paulo; Aparecida; Petropólis: Ave Maria, Loyola, Salesiana, Paulus, Paulinas; Santuário; Vozes, 2001.

A BÍBLIA DE JERUSALÉM. São Paulo: Paulus, 1985. 
A BíBliA SAgRADA. Traduzida de João Ferreira de Almeida. Revista e atualizada no Brasil. 2 ed. Barueri: SBB, 1993.

A BÍBLIA SAGRADA. Versão revisada da tradução de João Ferreira de Almeida, de acordo com os melhores textos em hebraico e grego. São Paulo; Rio de Janeiro: Candeia; IBB, 2000.

BÍBLIA SAGRADA. Nova Versão Internacional. São Paulo: Sociedade Bíblia Internacional, 2000.

BÍBLIA DO PEREGRINO. São Paulo: Paulus, 2002.

BIBLIA HEBRAICA STUTTGARTENSIA. Editio quarta ementada. Suttgart: Deutsche Bibelgesellschaft, 1990

BÍBLIA. Mensagem de Deus. São Paulo: Loyola, 1989.

BÍBLIA. Tradução ecumênica. 2 ed. São Paulo: Loyola, 1995.

Recebido em: 08/05/2018 Aceito em: 29/07/2018 Publicado em setembro de 2018 